\title{
COMMENTARY
}

\section{Our intellectual children: Kuhnian Ants or Feyerabendian Questioners?}

\author{
David Trafimow
}

\begin{abstract}
The philosophies of Kuhn and Feyerabend not only imply different ways to perform science, they also imply different ways to teach science, particularly at the graduate level. I am especially concerned about teaching at the graduate level in my area of psychology but the argument likely could be generalized outside of psychology. In essence, I argue that teaching graduate level psychology modeled after Feyerabend is better than modeled after Kuhn.
\end{abstract}

Keywords: Kuhn, normal science, Feyerabend, Questioner

\section{Introduction}

Although there has been long-standing debate about whether there has been a Kuhnian revolution in psychology with respect to the alleged cognitive revolution more than half a century ago ${ }^{[1,2]}$, there is little doubt that today psychology researchers mostly perform what Kuhn described as normal science ${ }^{[3]}$. Moreover, normal science thinking has pervaded graduate education, which is the issue of present concern ${ }^{[4,5]}$. Kuhn's normal science puzzle solving, not Feyerabend's emphasis on questioning basic assumptions, often has been touted as the best direction for training graduate students in research. For example, Gustafsson and Hagström ${ }^{[5]}$ asserted: "Constructing research puzzles is not the only method for justifying new research, but we contend it is among the best ones."

In graduate psychology programs all over the world, the students are expected to learn about their areas. They take graduate level courses, some of which feature content and others of which feature skills and methods. In addition, they are expected to learn on their own, particularly literature that is relevant to their specific research areas. However, it is possible to argue - and some have made this argument - that what is missing from graduate psychology programs is education in broader philosophy of science issues. For example, Gawronski and Bodenhausen ${ }^{[6]}$ have produced an edited book that addresses social psychology issues from philosophical perspectives

Received: June 8, 2019 Accepted: June 30, 2020 Published: July 1, 2020

* Correspondence to: David Trafimow, Psychology Department, MSC 3452, New Mexico State University, PO Box 30001, Las Cruces, NM 88003-8001, USA; Email: dtrafimo@nmsu.edu

Citation: Trafimow D. Our intellectual children: Kuhnian Ants or Feyerabendian Questioners?. Adv Educ Res Eval, 2020, 1(2): 88-92.

Copyright: $\odot 2020$ David Trafimow. This is an open access article distributed under the terms of the Creative Commons Attribution License, which permits unrestricted use, distribution, and reproduction in any medium, provided the original author and source are credited. precisely to remedy this lack in graduate education. Of course, whether this is a good idea depends on whether one believes that psychology graduate students ought to have philosophical training included in their graduate courses.

I wish to consider the issue from the perspectives of $\mathrm{Kuhn}^{[7]}$ and Feyerabend ${ }^{[8,9]}$. These are introduced briefly in the subsequent sections.

\section{Kuhn}

$\mathrm{Kuhn}^{[7]}$ described the history of science as characterized by long periods of 'normal science,' where researchers solve small puzzles, punctuated by rare 'revolutions' where basic assumptions are questioned. An important reason for the long periods of normal science is that scientific truth cannot be determined objectively and consequently is defined via consensus among scientists in the field. A key Kuhnian concept ${ }^{[7]}$ is incommensurability. According to Kuhn ${ }^{[7]}$, competing accounts are incommensurable because they not only are irreconcilable, but the terms have different usages in different accounts. For example, mass has a different meaning for Newton than for Einstein. For Newton, mass does not vary with velocity whereas for Einstein, it does. Thus, adherents of different accounts are not even speaking the same language, and so there is no way to definitively test competing accounts against each other. Note the contrast with Popper's falsificationist perspective ${ }^{[10]}$.

In the Kuhnian scheme, widespread agreement about basic assumptions is desirable in normal science periods because progress would be difficult to make if researchers were constantly debating them ${ }^{[11]}$. Thus, the questioning of basic assumptions is strongly discouraged and solving small puzzles is encouraged. Moreover, anomalous findings tend to be attributed to deviations on the part 
of the researcher rather than to basic assumptions being wrong. The extent to which Kuhn was describing what he perceived to be the history of science versus advocating for how science ought to proceed is not completely clear, but the consensus seems to be that Kuhn was advocating as well as describing. For present purposes, it is not important to resolve this issue; it is sufficient that Kuhn is popularly perceived as having advocated for normal science punctuated by rare revolutions. I will refer to this popular conception of Kuhn as the 'Kuhnian perspective.' Kuhn's influence was not limited to the physical sciences and philosophy of science, as he also has influenced the arts and humanities ${ }^{[12]}$, economics ${ }^{[13]}$, and political science $^{[14]}$

According to Kuhn, anomalies can accumulate to the point where normal science transitions into revolutionary science. In revolutionary science, the accumulation of anomalies renders competing accounts more sociologically acceptable, though incommensurability nevertheless prevents direct tests to distinguish them from the received account. That the very words used have different meanings for different accounts militates against the ability of scientists to make direct contrasts. Thus, even revolutionary science does not involve direct contrasts but rather comes down to a prolonged struggle where accounts lose because their adherents die out rather than because of empirical falsification.

However, not everyone agrees with Kuhn and his notion of incommensurability that plays such a foundational role in the persistence of normal science. Many have argued that even if theoretical terms, such as mass, are incommensurable, research findings are not ${ }^{[11]}$. Thus, although Newton and Einstein used mass in different ways, adherents of both accounts nevertheless could agree on the meaning of a clock reading. If the clock reading is more consistent with one account than with another account, that provides reason for favoring the former over the latter. A key point that Kuhn may have missed, but which was stressed by Lakatos ${ }^{[15]}$, is that auxiliary assumptions play a crucial role in connecting nonobservational terms in theories to observational terms in empirical hypotheses $^{[16-18]}$. Thus, with the help of auxiliary assumptions, incommensurability at the theoretical level need not imply incommensurability at the empirical level.

In summary, with the exception of rare revolutionary periods, normal science consists of solving small puzzles and avoiding questioning basic assumptions. From an education perspective, applying Kuhn would imply that students should simply accept what their teachers tell them about underlying assumptions, avoid questioning them, and absorb the lore that will enhance their puzzle-solving ability. However, as will become clear, it is possible to have a different education philosophy, based on the philosophical writings of Feyerabend ${ }^{[8,9]}$.

\section{Feyerabend}

In contrast to Kuhn, Feyerabend argued strenuously that it is good for scientists to question basic assumptions in their fields and not to succumb to their tyranny. For Feyerabend, science is essentially a creative enterprise and anything that stifles that creativity is a bad thing. For example, in his review of Galileo's contributions, Feyerabend argued that his rhetorical ability played an important role in furthering the Galilean revolution ${ }^{[19]}$. More generally, there is no single scientific method that all scientists follow or should follow, nor is it possible for philosophers to prescribe any single method; rather, Feyerabend felt that science could benefit from a dose of anarchy.

In contrast to Kuhn, Feyerabend did not endorse incommensurability. For Feyerabend, it did not matter whether theories are commensurable or incommensurable. Aside from the issue of demarcating that which is incommensurable from that which is commensurable, Feyerabend felt that one theory does not rule out another theory regardless of whether they are commensurable or incommensurable. Interestingly, Oberheim ${ }^{[20]}$ has argued that Feyerabend actually developed the notion of commensurability before Kuhn did, though the notion is more foundational for Kuhn than for Feyerabend.

Feyerabend's 'anything goes' philosophy has been criticized. If anything goes, then there is no way to demarcate science from non-science. Are psychic pronouncements, astrological proclamations, and so on as valid as serious work performed in a laboratory? Doubtless, even Feyerabend would not go that far. But not going that far implies the desirability of having some way to demarcate science from nonscience, and Feyerabend never provided that demarcation.

With respect to the argument to be made, Feyerabend's failure to specify demarcation criteria is not crucial. What is crucial is to appreciate the strong contrast between Kuhn's prescription regarding normal science, where basic assumptions are not questioned and should not be questioned, versus Feyerabend's more dynamic approach that encourages researchers to question basic assumptions. A quotation from Goddfrey-Smith dramatizes the contrast (pp. 112-113) and includes quotations from Feyerabend ${ }^{[8]}$.

"Science, for Feyerabend, has gone from being an ally of freedom to being an enemy. Scientists are turning into 'human ants,' entirely unable to think outside of their training (p. 188) ${ }^{[8]}$. And the dominance of science in 
society threatens to turn man into a 'miserable, unfriendly, self-righteous mechanism without charm or humour' ( $p$. $175)^{[8]}$."

Thus, we have a dramatic contrast whereby according to one perspective it is good for most scientists, at least in 'normal science' periods, not to question basic assumptions whereas according to the other perspective, it would be desirable to question basic assumptions. On the one hand, the goal is to have 'Kuhnian Ants' to perform normal science whereas on the other hand, the goal is to have 'Feyerabendian Questioners' to critically examine accepted scientific practices and resist their tyranny. I wish to provide the opportunity for the reader to face this issue frontally. Should graduate programs in psychology produce Ants or Questioners?

\section{Ants or Questioners?}

Let us suppose that we favor Kuhnian Ants; what does this imply about philosophy of science education in psychology graduate programs? Two obvious possibilities come to mind immediately. The first of these is that psychology graduate students should be required to read Kuhn, so that they can visualize the glories of being Ants. A potential problem with this approach is that Kuhn need not be interpreted in this way, and reading what Kuhn actually wrote might stimulate alternative interpretations. As an analogy, consider the problems in the history of Christianity after Luther translated the bible into the vernacular, so that many more people could read it, and come to their own conclusions that were not necessarily consistent with those of the Catholic Church ${ }^{[21]}$. If graduate students were to read Kuhn on a routine basis, some graduate students might decide that it would be more fun to cause a revolution than to perform normal science, which would push them away from being Kuhnian Ants.

Given the foregoing, it might be more effective to discourage any philosophical learning, or any learning whatsoever in anything other than psychology dogma. Ideal Ants would be trained to limit themselves to small questions to maximize busily carrying out the puzzle solving operations of normal science. As of now, of course, there are rewards for being Kuhnian Ants. It is easier to publish normal science manuscripts, get normal science grants, and get tenure for normal science, than to accomplish these ends by attempting revolutionary science ${ }^{[22]}$. Although this is scarcely necessary, given the effectiveness of current graduate programs in psychology in producing Kuhnian Ants, we could go a step further. We could elect a Pope in psychology to decide what questions the Ants would be allowed to pursue so as to prevent them from straying from the path of normal science.
Or we could go in the heretical route and train our graduate students in the philosophy of science and encourage them to question basic assumptions so that more of them become Feyerabendian Questioners. Instead of, or in addition to, performing twists on already published research - i.e., puzzle solving - perhaps graduate students could be trained to attempt strong tests of basic assumptions. We could even train them to question the education that we ourselves provide. This might lead to less normal science and more revolutionary science, and perhaps the notoriously slow progress in psychology could be quickened thereby.

Doubtless, when faced with the stark choice of training Ants or Questioners, a minority of psychology professors would admit to preferring the former to the latter. And yet, this is precisely what they accomplish in graduate education by obsessing over "content coverage" and ignoring the larger philosophical issues. So why do psychology professors, as a group, do it? Why train Ants when many psychology professors would at least give lip service to wanting to train Questioners? The answer, I think, is that psychology professors who are Feyerabendian Questioners are few and far between. If psychology professors were to train Feyerabendian Questioners, they would first have to train themselves to be that way. And how likely is that to happen?

In addition, there are many ways to avoid facing the Kuhnian Ant issue squarely with statements such as the following. (1) Graduate students need strong grounding in their areas. (2) Graduate students need to learn accepted practices in their areas. (3) Graduate students should be discouraged from attempting large leaps that they cannot make but should instead be taught to make incremental contributions that are feasible.

Statements 1 and 2 are not Kuhnian Ant ones by themselves; it depends on the unspoken additions. If an unspoken addition is, 'And so we need to train them to question the basic assumptions underlying the literature that we teach them,' Statements 1 and 2 would lean in the Feyerabendian Questioner direction. But if the unspoken addition is, 'And so philosophical discussion should take a back seat,' these statements lean in the Kuhnian Ant direction. To anyone who has been through a graduate program, it is self-evident that unspoken additions are far more likely to lean in the Kuhnian Ant direction than in the Feyerabendian Questioner direction. Again, this is due at least in part to the fact that few psychology professors are Feyerabendian Questioners and lack the ability to train their graduate students in that way.

The third argument leans in the Kuhnian Ant direction, even without any unspoken additions. Here the professor takes it as given that being a Kuhnian Ant is the best that 
is possible and that trying for more than that will simply impede graduate students from succeeding at that which is possible, being good Kuhnian Ants. I wish that I had money for every time I have heard a professor push in this direction at M.A. or $\mathrm{PhD}$ committee meetings.

It would be remiss of me not to address ethical concerns. Because it is obvious that career 'success' is more likely via the Kuhnian Ant way than via the Feyerabendian Questioner way, one could argue that our first duty is to train graduate students to become Kuhnian Ants so that they can be successful. Anything that detracts from that, such as Feyerabendian questioning, is against their interests and is consequently unethical. Thus, in the interest of ethics, psychology professors are right to be Kuhnian Ants and to train students to be so as well.

Even granting the major premise of the foregoing argument, which is debatable, it is possible to come to a different conclusion by widening the horizon of discourse. As psychology professors we have a general duty to perform towards humanity, and part of that duty is to make psychology as good as possible. Because it is the Feyerabendian Questioners who make the big contributions and cause the big changes, it is best for humanity, in general, to have more Feyerabendian Questioners. Frankly, no matter what we do, there will always be plenty of Kuhnian Ants; we will not run out of them! But there seems to be a perennial shortage of Feyerabendian Questioners, and so our general duty as teachers and mentors is to produce more of them.

Even from the point of view of the individual graduate student, it is possible to refute the argument that it is in this person's best interest solely to be trained as a Kuhnian Ant. This is the comfortable way to go but it also is the boring way to go, as Popper ${ }^{[10]}$ suggested in his famous statement: "In my view, the "normal' scientist, as Kuhn describes him, is a person one ought to feel sorry for" (p. 52). Is it really all that ethical to doom our graduate students to comfortable but boring lives? Shouldn't we at least give them the option to choose whether to go for comfort or excitement? If the only training our graduate students receive is in how to be good Kuhnian Ants, this is a step in the direction of depriving them of the option to choose. All things considered I believe that ethical concerns militate in the direction of at least some training in how to be a Feyerabendian Questioner. Students ought to at least be told that it is possible to question basic assumptions.

\section{Conclusion}

By engaging in all the foregoing, I have painted myself into a corner. On the one hand, I wish to advocate for training graduate students to be Feyerabendian Questioners as opposed to Kuhnian Ants. On the other hand, I freely admit my opinion that few psychology professors have the capability to train graduate students in the direction that I advocate. Am I arguing for that which is impossible? Am I engaging in a pointless exercise?

Possibly not, as there are ways to circumvent the difficulty. The most obvious way would be for psychology professors to improve themselves by studying the history of their own science and of other sciences, and also to study the philosophy of science. Given human nature and the 'iron rice bowl' of tenure, this is not likely to happen. Is there another way to go?

I think there is. Although most psychology professors are Kuhnian Ants, there are some who are not. It is possible to leave the Kuhnian Ant training in the hands of the majority of psychology professors who are that way and leave the Feyerabendian training to the few professors who are not Kuhnian Ants. Because many psychology departments are large, it is reasonably likely that there is at least one member of a reasonably large psychology department who does enjoy questioning basic assumptions. So, the professors who are Kuhnian Ants do not actually have to become Feyerabendian Questioners, it is sufficient for them to recognize that it is a good idea to expose their graduate students to the few who are. A couple of graduate courses taught by a Feyerabendian Questioner might be sufficient to at least provide the possibility for some of the graduate students to rise above the mediocrity of the Kuhnian Ant Kingdom.

\section{References}

[1] Briskman LB. Is a Kuhnian Analysis Applicable To Psychology? Social Studies of Science, 1972, 2(1): 87-97. https://doi.org/10.1177/030631277200200103

[2] Weimer WB and Palermo DS. Paradigms and Normal Science in Psychology. Social Studies of Science, 1973, 3(3): 211-244. https://doi.org/10.1177/030631277300300301

[3] Forrester J. On Kuhn's Case: Psychoanalysis and the Paradigm. Critical Inquiry, 2007, 33(4): 782-819. https://doi.org/10.1086/521570

[4] Irez S and Han C. Educational reforms as paradigm shifts: Utilizing Kuhnian lenses for a better understanding of the meaning of, and resistance to, educational change. International Journal of Environmental \& ence Education, 2011, 3(6): 251-266.

[5] Gustafsson K and Hagström L. what is the point? teaching graduate students how to construct political science research puzzles. European Political Science, 2018, 17(4): 634-648. https://doi.org/10.1057/s41304-017-0130-y

[6] Gawronski B and Bodenhausen G. Theory and Explanation in Social Psychology. Guilford Press, 2015. 
[7] Kuhn TS. The structure of scientific revolutions. Chicago: University of Chicago Press, 1962.

[8] Feyerabend P. Against method: Outline of an anarchistic theory of knowledge. Atlantic Highlands, NJ: Humanities Press, 1975.

[9] Feyerabend P. Against method (3rd Edition). London: Verso, 1993

[10] Popper KR. Normal science and its dangers. In Imre Lakatos and Alan Musgrave (Eds.), Criticism and the growth of knowledge (Vol 4, pp. 51-58), Cambridge, Cambridge University Press, 1970.

[11] Godfrey-Smith P. Theory and reality: An introduction to the philosophy of science. Chicago: The University of Chicago Press, 2003.

[12] Harris ME. The notion of papal monarchy in the thirteenth century: the idea of paradigm in church history. Lewiston NY: Edwin Mellen Press, 2010.

[13] Mehta G. The Structure of the Keynesian Revolution, London: Martin Robertson, 1977.

[14] Ryan A. Paradigms lost: How Oxford escaped the paradigm wars of the 1960s and 1970s. In C. Hood, D. King, and G. Peele (Eds.), Forging a discipline (pp. 86-103). Oxford, UK: Oxford University Press, 2014.

[15] Lakatos I. The methodology of scientific research programmes. Cambridge, UK: Cambridge University Press, 1978
[16] Trafimow D. The Theory of Reasoned Action: A Case Study of Falsification in Psychology. Theory \& Psychology, 2009, 19(4): 501-518 https://doi.org/10.1177/0959354309336319

[17] Trafimow D. The role of auxiliary assumptions for the validity of manipulations and measures. Theory \& Psychology, 2012, 22(4): 486-498 https://doi.org/10.1177/0959354311429996

[18] Trafimow D and Rice S. The role of auxiliary assumptions in the falsification of ergonomics theories. Theoretical Issues in Ergonomics Science, 2010, 12(12): 220-229. https://doi.org/10.1080/14639220902853070

[19] Hickey TJ. Understanding Feyerabend on Galileo. Irish Theological Quarterly, 2009, 74(1): 89-92. https://doi.org/10.1177/0021140008098846

[20] Oberheim E. Feyerabend's Philosophy. Berlin, Germany: Walter de Gruyter GmbH \& Co., 2006.

[21] Durant W. The reformation. New York: Simon and Schuster, 1957.

[22] Agnew NM and Pyke SW. The science game: An introduction to research in the behavioral and social sciences. Oxford, UK: Oxford University Press, 2007. 